Respiration 2014;88:521-522

DOI: $10.1159 / 000368616$

\section{Utilizing an Endobronchial Blocker and a Flexible Bronchoscope for Transbronchial Cryobiopsies in Diffuse Parenchymal Lung Disease}

\section{Laurie A. Hohberger, Zachary S. DePew, James P. Utz, Eric S. Edell,} Fabien Maldonado

Division of Pulmonary and Critical Care Medicine, Mayo Clinic, Rochester, Minn., USA

Conventional bronchoscopic lung biopsies play a minimal role in the diagnosis of diffuse parenchymal lung diseases due to the small sample size and crush artifact of the biopsied specimen [1]. Recently, transbronchial cryobiopsies have shown promise in their diagnosis [2-4]. However, given the limited experience with cryobiopsies for this purpose to date, pneumothorax and bleeding risk will remain a concern until more safety data become available. To manage the potentially increased bleeding risk, the preemptive placement of a deflated endobronchial blocker in the airway of the lung being biopsied has been described $[1,5,6]$. However, a rigid tracheoscope is generally needed because the luminal diameter of regular-size endotracheal tubes is typically insufficient to accommodate both a bronchoscope and a blocker simultaneously [1]. Additionally, a technique using a supraglottic airway with general anesthesia has also been described to accommodate the need for both an endobronchial blocker and a flexible bronchoscope in the central airways [5]. Here, we describe a new technique that does not require rigid bronchoscopy or general anesthesia.

An 8.0 Smiths ${ }^{\circledR}$ cuffed wire spiral endotracheal tube is loaded over the flexible bronchoscope. Without the use of the multiport airway adapter, the guide loop of a lubricated and deflated Arndt endobronchial blocker is secured around the distal tip of the bronchoscope (fig. 1a, b). The patient is then fiberoptically intubated using the flexible bronchoscope, with the endobronchial blocker riding alongside the bronchoscope and the endotracheal tube through the oropharynx, larynx, and central airways (fig. 1c). Once the endobronchial blocker has been directed into the main stem bronchus on the side to be biopsied, the guide loop is loosened, releasing it from the bronchoscope, where it remains in position (fig. 1d). The bronchoscope is withdrawn to the mid-trachea and the patient is fiberoptically intubated with the endotra-

Fig. 1. a The complete setup of the flexible bronchoscope (black arrow), endotracheal tube (white arrow), and endobronchial blocker (white arrowhead). Note that the endobronchial blocker is attached via the guide loop to the distal end of the bronchoscope, while the endotracheal tube is loaded onto the bronchoscope in the usual fashion. b A close-up view of the guide loop (black arrow) of the endobronchial blocker (yellow and blue structure) secured around the distal end of the bronchoscope. c The bronchoscope (black arrow) and the endobronchial blocker (white arrowhead) passing through the vocal cords en bloc. $\mathbf{d}$ The endobronchial blocker positioned in the proximal right main stem bronchus following release of the guide loop from the bronchoscope. The white arrow points to the main carina.
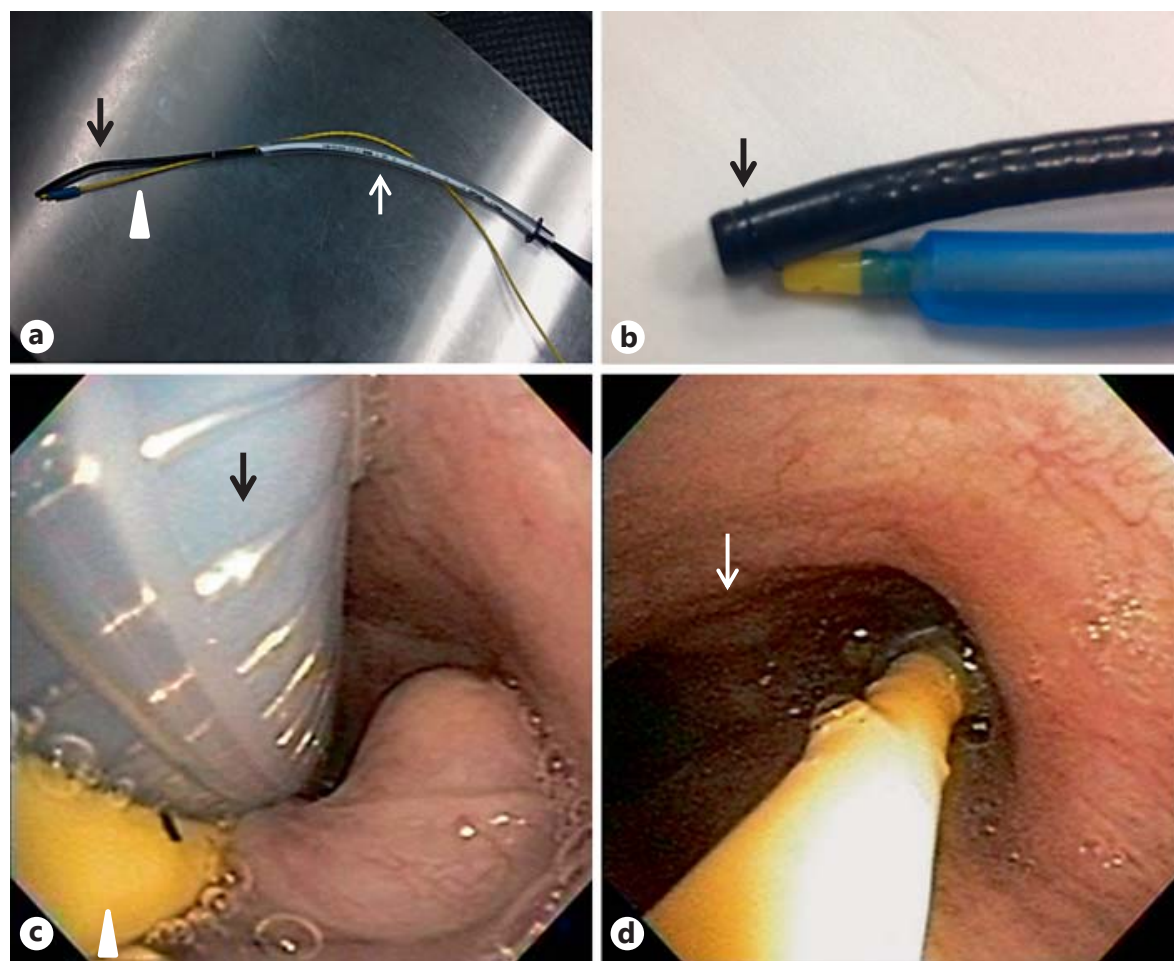

\section{KARGER}

E-Mail karger@karger.com www.karger.com/res (c) 2014 S. Karger AG, Basel

0025-7931/14/0886-0521\$39.50/0
Fabien Maldonado, MD

Division of Pulmonary and Critical Care Medicine

Mayo Clinic, 200 First Street SW

Rochester, MN 55905 (USA)

E-Mail Maldonado.fabien@ mayo.edu 
cheal tube positioned several centimeters above the main carina. We have found that the flexible bronchoscope can easily pass through the endotracheal tube and past the deflated endobronchial blocker en route to the site of biopsy. The cryoprobe is then introduced through the working channel of the bronchoscope, and biopsies are obtained under fluoroscopic guidance as previously described [1-4]. The endobronchial blocker remains deflated unless needed to assist in controlling bleeding. Upon completion of the procedure, the endobronchial blocker is removed en bloc with the endotracheal tube when the patient is clinically ready for extubation.

Cryobiopsies show promise in the diagnosis of diffuse parenchymal lung diseases. While multiple small studies have reported no increased risk for significant bleeding $[1-4,6]$, experience with transbronchial cryobiopsy is still limited, and concerns regarding potential complications remain. Use of an endobronchial blocker is helpful to manage procedurally related hemorrhage. Being able to utilize the endobronchial blocker without the use of rigid bronchoscopy increases its availability to bronchoscopists without significant rigid bronchoscopy experience and allows for safer performance of peripheral cryobiopsies.
Financial Disclosure and Conflicts of Interest

The authors have no potential conflicts of interest to report.

\section{References}

1 Yarmus L, Akulian J, Gilbert C, et al: Cryoprobe transbronchial lung biopsy in patients after lung transplantation: a pilot safety study. Chest 2013;143:621-626.

2 Kropski JA, Pritchett JM, Mason WR, et al: Bronchoscopic cryobiopsy for the diagnosis of diffuse parenchymal lung disease. PLoS One 2013; 8:e78674.

- 3 Babiak A, Hetzel J, Krishna G, et al: Transbronchial cryobiopsy: a new tool for lung biopsies. Respiration 2009;78:203-208.

4 Fruchter O, Fridel L, Rosengarten D, et al: Transbronchial cryobiopsy in immunocompromised patients with pulmonary infiltrates: a pilot study. Lung 2013;191:619-624.

5 Sastre JA, Cordovilla R, Jimenez MF, et al: Management of a transbronchial cryobiopsy using the i-gel airway and the Arndt endobronchial blocker. Can J Anaesth 2014;61:886-888.

6 Pajares Ruiz V, Torrego Fernández A, Puzo Ardanuy C, Gil de Bernabé A, et al: Use of an occlusion balloon in transbronchial lung cryobiopsy. Arch Bronconeumol 2014;50:309-310.

\section{Erratum}

The authors of the article entitled 'Stent-mediated gene delivery for site-specific transgene administration to the airway epithelium and management of tracheobronchial tumors' [Respiration 2014;88:406-417, DOI: 10.1159/000368164] wish to publish the following correction.

On page 406 the name of an author, Dr. Ivan S. Alferiev, is missing. The correct author list should be as follows:

\section{Robert J. Kruklitis ${ }^{c} \quad$ Ilia Fishbein $^{\mathrm{b}} \quad$ Sunil Singhal $^{\mathrm{a}} \quad$ Veena Kapoor $^{\mathrm{a}}$ Robert J. Levy ${ }^{\mathrm{b}}$ Ivan S. Alferiev ${ }^{\mathrm{b}}$ Daniel H. Sterman ${ }^{\mathrm{a}}$}

aSection of Interventional Pulmonology and Thoracic Oncology, Pulmonary, Allergy and Critical Care Division, University of Pennsylvania Medical Center, and ${ }^{b}$ Division of Pediatric Cardiology, Children's Hospital of Philadelphia, Philadelphia, Pa., and ${ }^{\mathrm{c}}$ Division of Pulmonary and Critical Care, Lehigh Valley Health Network, Allentown, Pa., USA 